\title{
A Time to Remember: The Fiftieth Anniversary of the Faculty of Philosophy, Sciences and Letters at Ribeirão Preto, University of São Paulo
}

We are celebrating the $50^{\text {th }}$ anniversary of the Faculty of Philosophy, Sciences and Letters at Ribeirão Preto, University of São Paulo (FFCLRP-USP) and the Department of Psychology, which was created on the occasion of the foundation of the School and started its classes on March $31^{\text {st }} 1964$. Besides its regular teaching and community service activities, research at the Department is basically organized around two Graduate Programs: in Psychobiology and in Psychology, both of which offer the Master's and Ph.D. levels and have been granted score 7 and 5, respectively, in the most recent Coordination for the Improvement of Higher Education Personnel (CAPES) ranking. Various Research Groups are active at the Department of Psychology, which are registered at the National Council for Scientific and Technological Development (CNPq) and develop research projects in their laboratories that receive regular funding from different agencies.

The Graduate Program in Psychology started its activities in February/March 1995 and offers the Academic Master's and Ph.D. programs. Paidéia is the Program's fourmonthly publication, which has been issued since 1991 and is indexed in more than ten Brazilian and international databases. On the occasion of the $50^{\text {th }}$ anniversary of FFCLRP-USP, as the Editor, I would like to extend my sincere acknowledgements to the entire Paidéia team, comprising an Editorial Board of associate editors who are renowned researchers in Psychology. Furthermore, the hard work of managing this journal counts on the editorial support of a competent technical team and grantees. We are also grateful to the coordination of the Graduate Program in Psychology, to the Head of the Department of Psychology and to the Dean's Office of FFCLRP-USP, who have spared no efforts to support the journal.

In the CAPES Ranking of Journals Qualis, Paidéia figures among the select group of A1 journals in Psychology, which certifies the level of excellence achieved in its 22 years of existence. The results of last year's editorial process have been systemized in this issue (Santos, 2014). In fact, this issue 57, volume 24 of Paidéia, opens with the Management Report - 2013, which preserves the tradition of presenting to the scientific community a balance of what the journal has produced in the previous year.

By publishing the Management Report 2013, we proceed with the policy of publishing the most important indicators of the manuscript flow, in the different phases along its track from the submission to the approval (or rejection) and publication. The data show that the time between the submission and publication remains positive, although plenty remains to be done to speed up the review process and shorten the duration of the procedure. The pre-analysis of submitted manuscripts has functioned satisfactorily, so that the authors rapidly receive feedback as to the need for formal adjustments in the text.
The Management Report also shows that we are gradually expanding the regional and institutional range of origin of the papers and the ad hoc advisors. Our investments to have the journal indexed in international databases have also been successful. In 2013, we have conquered new databases: ProQuest, EBSCO, Cengage Learning and Dialnet. Renewed efforts are being undertaken and we are hoping to get further good news in this area as well in 2014.

Different strategies have been adopted to attract contributions for review. Continuing efforts are undertaken to insert the journal at the international level through the publication of the full texts in English. All abstract are compulsorily published in Portuguese, English and Spanish. Translators accredited by the journal, with considerable expertise in the translation of scientific texts, translate the texts into English. It is important to highlight that Paidéia does not maintain any kind of contract with these accredited translators, nor with the international translation companies. The authors are free to choose from the list of accredited professionals and should settle the translation costs, which is part of common practice in different journals in the health area.

We are convinced that Paidéia has offered its contribution to the development of a world-class university (Toledo, 2014). It would be interesting for the Brazilian Psychology journals to adopt the habit of publishing their management reports to unveil aspects of the knowledge qualification and dissemination. That would allow us to compare the journals with a view to contributing to the improvement and strengthening of all publications. These reports should particularly disseminate those aspects that remain more invisible to the readers and authors of the papers, related to the outcomes of the editorial process and the work of the editors in command of their journals.

The article entitled Scale of Family Unpredictability During Childhood: Validity Evidence, authored by Anna Beatriz Carnielli Howat-Rodrigues from Universidade de São Paulo, and Rosana Suemi Tokumaru from Universidade Federal do Espírito Santo, Brazil, examined evidence of validity for the Brazilian version of the Scale of Family Unpredictability during childhood (EIFI). A total of 740 people participated in the study. A significant effect of all unpredictability factors on the purchasing power of the participants was found, confirming validity by contrasting groups of EIFI: people belonging to socioeconomic classes with lower purchasing power presented higher family unpredictability during childhood. We concluded that the three-dimensional EIFI is psychometrically adequate, allowing the differentiation of groups in the constructs evaluated.

The article Influence of Psychological, Anthropometric and Sociodemographic Factors on the 
Symptoms of Eating Disorders in Young Athletes, by Leonardo de Sousa Fortes and Maria Elisa Caputo Ferreira from Universidade Federal de Juiz de Fora, and Sebastião de Sousa Almeida from Universidade de São Paulo, Brazil, analyzed the influence of psychological, anthropometric and sociodemographic factors on the risk behaviours for eating disorders (ED) in young athletes. Participants were 580 adolescents of both sexes. A multiple regression indicated that body image dissatisfaction (BD) and percentage of fat significantly modulated the variance of females' scores on the Eating Attitudes Test (EAT-26), whereas BD, degree of psychological commitment to exercise (DPCE), fat percentage, age, ethnicity and competitive level significantly explained the variance of risk behaviours for males' ED. Thus, only BD influenced risk behaviours for ED in both sexes.

Then, the article Cattell's Personality Factor Questionnaire (CPFQ): Development and Preliminary Study, by Ricardo Primi, Carla Fernanda Ferreira-Rodrigues and Lucas de Francisco Carvalho from Universidade São Francisco, Brazil, aimed to develop an instrument for personality assessment according to Cattell's model and to carry out an empirical analysis of the internal structure of the instrument. Three hundred and forty-seven people, mostly female, participated in the study. The results suggest that the instrument is composed of 12 factors of reasonable internal consistency rates. The model developed by Cattell helped to understand the structural organization found for the instrument, since there is coherency, especially in relation to more general terms (global factors).

The study Mobbing of Working Students, written by Alessandra Rodrigues Jacoby from Faculdades Integradas de Taquara, and Janine Kieling Monteiro from Universidade do Vale do Rio dos Sinos, Brazil, investigated the prevalence of mobbing in relation to university students who work and also the most frequent biosociodemographic and work characteristics of the group who were mobbed. The sample was composed of 457 working students living in the metropolitan area of Porto Alegre, in the state of Rio Grande do Sul. High rates of the practice of hostile acts in the workplace can be noted, but these are often viewed as mundane and normal acts in the workplace. In conclusion, it is necessary to seek alternatives in order to overcome this problem, which already affects a significant number of workers.

Subsequently, the article Sources and Reactions to Stress in Brazilian Lawyers, authored by Maria de Fátima Antunes Alves Costa from UNIABEU Centro Universitário, and Maria Cristina Ferreira from Universidade Salgado de Oliveira, Brazil, aimed to analyze the predictive power of seven stressors (decision latitude, psychological demands at work, physical demands at work, social support from colleagues, ergonomic stressors, relationships with clients, job insecurity) for job dissatisfaction, depression and psychosomatic problems in a sample of 702 Brazilian lawyers. The results showed that decision latitude and social support were the main negative predictors of stress, while psychological demands and job insecurity were its main positive predictors. These results are discussed in the light of the demand-support-control model, which was used as a framework for the research.

The study Assessment of Distress Among Chemotherapy Patients: A Comparative Study of Gender, by Cristiane Decat Bergerot, Tereza Cristina Cavalcanti Ferreira de Araujo, and Bartholomeu Tôrres Tróccoli from Universidade de Brasília, Brazil, aimed to evaluate, analyze and understand distress levels experienced during chemotherapy treatment, comparing men and women. The sample was composed of 328 patients recruited from an Oncology center. Comparatively, the incidence of distress was higher among women, who also reported the highest number of problems in the practical, family, emotional, spiritual and physical domains. The results corroborate the international literature on the subject. Clinical interest of systematic assessment of distress was confirmed to develop routines of therapeutic monitoring adapted to the specific needs of cancer patients.

The article Coping Strategies Among Brazilian Pregnant Women Living With HIV, authored by Evelise Rigoni de Faria from Grupo Hospitalar Conceição, Tonantzin Ribeiro Gonçalves from Universidade do Vale do Rio dos Sinos, Fernanda Torres de Carvalho from Secretaria de Saúde do Estado do Rio Grande do Sul, Rita de Cássia Sobreira Lopes and Cesar Augusto Piccinini from Universidade Federal do Rio Grande do Sul, Brazil, aimed to describe coping strategies of pregnant women living with HIV (PWLH). This cross-sectional survey involved 77 PWLH from a public health care center in Brazil. Coping was measured for three types of strategies: Problem-focused, Emotion-focused, and Relationship support. Findings underline the need for HIV interventions focused on social support and participation by the baby's father, with particular attention to those PWLH who were recently diagnosed and economically vulnerable.

The following article, Emergence of Reading and Writing in Illiterate Adults After Matching-to-Sample Tasks, written by Carmen Silvia Motta Bandini and Heloisa Helena Motta Bandini from Universidade Estadual de Ciências da Saúde de Alagoas, Brazil, Ana Carolina Sella from University of Nebraska Medical Center, USA, and Deisy das Graças de Souza from Universidade Federal de São Carlos, Brazil, which is divided into two studies, aimed to assess the effects of a Portuguese language reading curriculum for simple (Study 1) and complex words (Study 2) in illiterate adults. Four participants took part in each study. In both studies, reading was taught mainly by training dictated words to printed words relations. Overall, there was an increase in the percentage of correct responses in reading and writing tasks when pre-tests and post-tests were compared; results were more consistent in reading tasks.

The study entitled Executive Functions in Children and Adolescents With Autism Spectrum Disorder, by 
Fernanda Rasch Czermainski and Rudimar dos Santos Riesgo from Universidade Federal do Rio Grande do Sul, Luciano Santos Pinto Guimarães from Hospital de Clínicas de Porto Alegre, Jerusa Fumagalli de Salles and Cleonice Alves Bosa from Universidade Federal do Rio Grande do Sul, Brazil, aimed to investigate executive function and working memory in children and adolescents with Autism Spectrum Disorder (ASD) compared to children and adolescents with typical development matched by age, formal education, and nonverbal IQ. The tests used were Raven's Colored Progressive Matrices, Stroop Test, Trail Making Test, Rey's Complex Figure Test, Digit span, Pseudowords span, Working memory, Verbal fluency (orthographic and semantic) and Go/no go. The results demonstrate impairment of executive function in the clinical group, especially in planning, flexibility, inhibition, and also visuospatial working memory.

The next article, Criteria of Progress in Children Psychotherapies According to Psychotherapists, written by Lilian Pereira de Medeiros Guimarães and Elisa Medici Pizão Yoshida from Pontifícia Universidade Católica de Campinas, Brazil, performed a survey with psychotherapists, regarding the criteria they consider relevant to measure the progress of children in psychotherapy and whether the criteria indicated by them differ according to the therapist's theoretical approach. Participants were 154 child therapists from different regions of Brazil. The analysis regarding the criteria of positive change that the participants indicated and their theoretical approach suggested that, despite the theoretical differences, in practice psychotherapists seem to adopt similar criteria to interpret progress in child psychotherapies. The criteria mentioned may be useful for a better systematization of the psychotherapy techniques for children. However, due to the lack of elements to evaluate the sample's representativeness, caution is advised in generalizing the results.

Then, the article Love and Marital Quality in Romantic Relationships Mediated and Non-Mediated by Internet, by Karla Rafaela Haack and Denise Falcke from Universidade do Vale do Rio dos Sinos, Brazil, compared the three elements of love (intimacy, passion and decision/commitment) and marital quality of 86 Internet users (43 in a relationship mediated by the Internet and 43 with a physical relationship). The results indicate that there is a significant difference in the intimacy, the decision/commitment and the whole dimension of love, as well as in the marital quality between partners who have a relationship mediated by Internet and the ones in a physical relationship. We can conclude that the Internet is a great tool for people to meet, but that it is important for the relationship to develop in a face-to-face context.

The article Smartphones and Location Awareness in Brazil: Users' Reactions, authored by Ana Maria Nicolacida-Costa and Mariana S. Matos-Silva from Pontifícia Universidade Católica do Rio de Janeiro, Brazil, aimed at gaining detailed information on how Brazilians react to and deal with the novelty presented by location awareness, especially in LBSN applications. Fifteen knowledgeable users of digital technologies aged between 23 and 38 were recruited in Rio de Janeiro and São Paulo. Results revealed that location-sharing reinforced their pre-existing fears related to violence and criminality. Therefore, in order to protect their personal safety most participants avoided location-disclosure. The fears mentioned by them are embedded in the violent context they live in.

Concluding this issue, the study entitled The Defense of Socio-Educational Internment: Feature of the Hygienist Principles, written by Juliana Biazze Feitosa from Centro de Socioeducação II, and Maria Lúcia Boarini from Universidade Estadual de Maringá, Brazil, evaluated the existence of the aspects contained in the justifications of hygienism judgments of teenagers who meet admission youth work. In this sense, we analyzed 21 sentences that determined the internment and its supporting materials which makes up the judicial process of teenagers that have entered the year 2010 in the Center of Socio- education II in Cascavel Paraná State. The results led us to conclude that nowadays, notwithstanding the Child and Youth Statute, we are still, by judicial determination, removing the Teen Delinquency situation and closed the judicial term returning it to the same context from which it was withdrawn.

This issue closes with the Paidéia Publication Guidelines. We hope the readers can appreciate the richness of the contributions and have a fruitful reading.

Manoel Antônio dos Santos Editor

\section{References}

Toledo, K. (2014). Especialistas defendem desenvolvimento de universidades de classe mundial. Pesquisa FAPESP. Retrieved from http://agencia.fapesp.br/18521

Santos, M. A. (2014). Paidéia: Management report - 2013. Paidéia (Ribeirão Preto), 24(57), 5-9. doi:10.1590/1982-43272457201402

\section{How to cite this editorial:}

Santos, M. A. (2014). A time to remember: The fiftieth anniversary of the Faculty of Philosophy, Sciences and Letters at Ribeirão Preto, University of São Paulo. [Editorial]. Paidéia (Ribeirão Preto), 24(57), 1-3. doi:10.1590/1982-43272457201401 


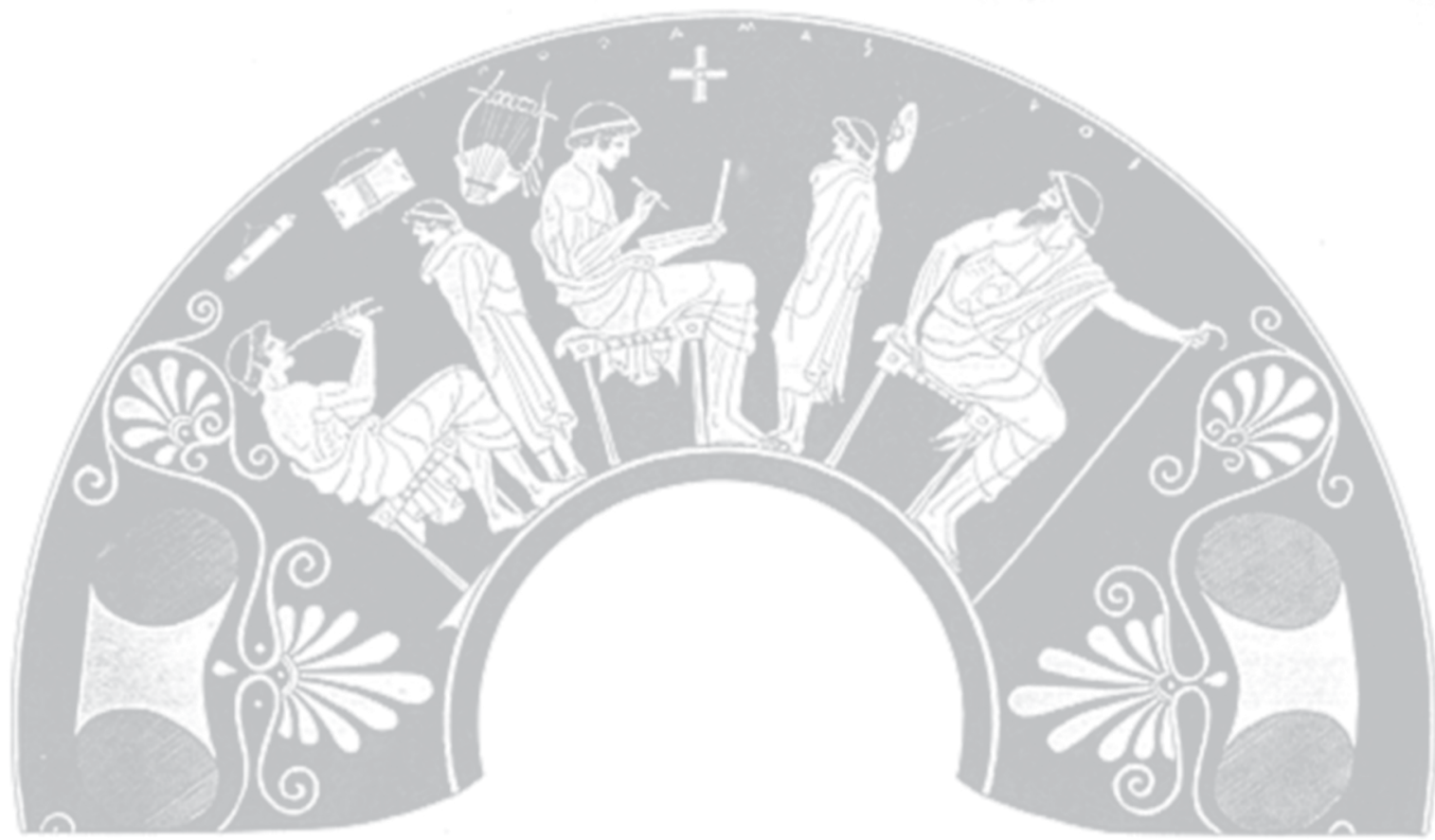

